\title{
The wisdom of crowds
}

\section{Climate change is inherently a social problem — so why have sociologists been so slow to study it? Kerri Smith reports.}

W hen was the last time you tried to convince your partner or a friend to do something for you? Washing the dishes, say - something you have to do, but you'd rather put off until later. The negotiation probably involved some coaxing and complementing, and then possibly some complaining or coercion. That's quite a lot of diplomacy for a situation involving two people and a minor task. Now imagine groups of hundreds of people trying to get thousands of people to do what they want them to. It's headspinning stuff, but it's what the world is up against when it comes to dealing with climate change.

What's more, scientists who spend their time measuring the rate of ice melting in the Arctic or working out the chemistry of storing carbon underground aren't likely to solve this thorny problem. Luckily, there is a field of study that has at its heart human activity and social structure - why and how we do what we do. That discipline is sociology.

"Climate change is the ultimate collective-action problem," says Steven Brechin, a sociologist at Syracuse University in New York. "How do you get people to agree in the short term to solutions for a long-term problem?" The answer, like the problem, has to be wide-ranging and global, says Jeffrey Broadbent of the University of Minnesota in Minneapolis, who also studies how societies affect their environments. "Its only solution lies in a level of global cooperation that humanity has never seen before."

\section{IN SHORT SUPPLY}

Broadbent is just starting to investigate what factors contribute to this kind of cooperation at the national level. $\mathrm{He}$ has recently begun a project, called Comparing Climate Change Policy Networks, that aims to find out how information about climate change enters a particular country's network of interested parties and what happens to it once it's found its way to organizations and governments.

Broadbent is now one of a band of sociologists that has begun to turn the

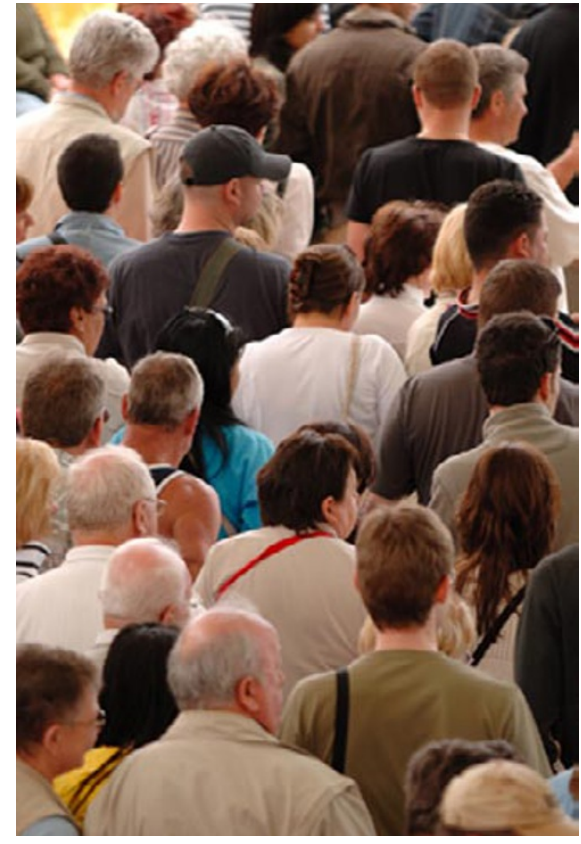

1992, three per cent of funding from the GCRP was spent on human dimensions research, including social science, and now this figure has dropped to less than two per cent. Diana Liverman, co-director of the Institute for Environment and Society at the University of Arizona in Tucson and director of the Environmental Change Institute at the University of Oxford, agrees with Stern: "Funding for social-science approaches to climate change has been pathetic given the size of the research challenge we're facing."

In the United Kingdom, some are concerned that a government desire to ring-fence funding for 'hard' disciplines such as science, engineering and maths will adversely affect the ability of sociologists and other social scientists to focus their research on climate change. This may be shifting, however, with funding for natural and social scientists to collaborate increasing both in the UK and the US.

But whether sociologists will avail themselves of such opportunities is another issue. First, they would probably have to overcome some of the organizational issues within sociology itself. Like most academic disciplines, sociology is split into subfields, many of which don't mix on anything like a day-to-day basis.

Environmental sociology, which In May last year, over 30 sociologists met at the US National Science Foundation's headquarters in Arlington, Virginia, to discuss what sociology is already contributing to climate change research and what questions sociologists need to be answering next. "Purely technological 'fixes", concluded the meeting report, "will not be sufficient to mitigate or successfully adapt to climate change."

But this can-do attitude hasn't always been in evidence. "There are a lot of valuable contributions that could be made, and very few of them have been made," says Paul Stern, director of the US National Academies Committee on the Human Dimensions of Global Change. That's partly for financial reasons: funding from the US Global Change Research Program (GCRP, formerly the Climate Change Science Program) for research on the 'human dimensions' of climate change has actually fallen in the last 20 years. In has its roots in the 1970s environmental movement, fits most naturally into a climate change research remit. But despite the field's endurance, environmental sociologists are rather isolated from the discipline's mainstream, featuring sparsely at the bigger conferences and publishing in different journals.

The American Sociological Review, for example, has published "literally a handful" of papers on environmental studies in the last three decades, says Thomas Dietz, director of the Environmental Science and Policy Program at Michigan State University in East Lansing. According to Dietz, who works at the boundary of environmental science, sociology and human ecology, "Sociology in the US sees environment as not unimportant - but not core."

That traditional core of sociology has instead been "tied into just looking 
at people", says Broadbent, with its focus purely on the interactions going on between people, societies or nations. "What we've had very often is the idea that nature is somehow a stable, unchanging background concept," says Constance Lever-Tracy, a sociologist studying migration at Flinders University in Adelaide, Australia. Lever-Tracy was compelled by these issues to write an article for the journal Current Sociology last year drawing attention to the fact that her clan have had surprisingly little to say about climate change ${ }^{2}$. "Sociology tries to say something about everything, but to my surprise I found almost nothing," she says.

Liverman, too, has noticed these disciplinary issues. "My two institutions - Oxford and Arizona - really haven't been able to engage sociologists in climate change," she says. And why? "This is a caricature, but they tend to be more interested in general theories rather than specific topics." Differences in how research gets done can cut both ways. "Physical scientists can be a bit sniffy about qualitative science," says Brian Hoskins, director of the Grantham Institute for Climate Change at Imperial College London. At the same time, "social scientists use jargon with the expectation that physical scientists will understand it", he says.

\section{SELFISH CITIES}

Despite these obstacles, sociologists are beginning to look at how groups of people - at various scales - can tackle the problem. While Broadbent chose the national level, for example, others are looking at communities or municipalities, and some are scaling right down to individual families.

Sammy Zahran at Colorado State University in Fort Collins began his approach with a simple, if somewhat cynical, question about what makes local governments participate in programs to lower carbon emissions. His interest was piqued by the success of a program called Cities for Climate Protection, which encourages local governments around the world to reduce emissions and improve air quality.

"From a strictly rational-choice perspective", queries Zahran, "why would a local government assume the costs of a program like this when the expected benefits are low?" In other words, he asked, is there a mathematical logic behind an area's response to climate change? He and his colleagues chose 150 localities in the United States - defined as county governments, metropolitan areas or

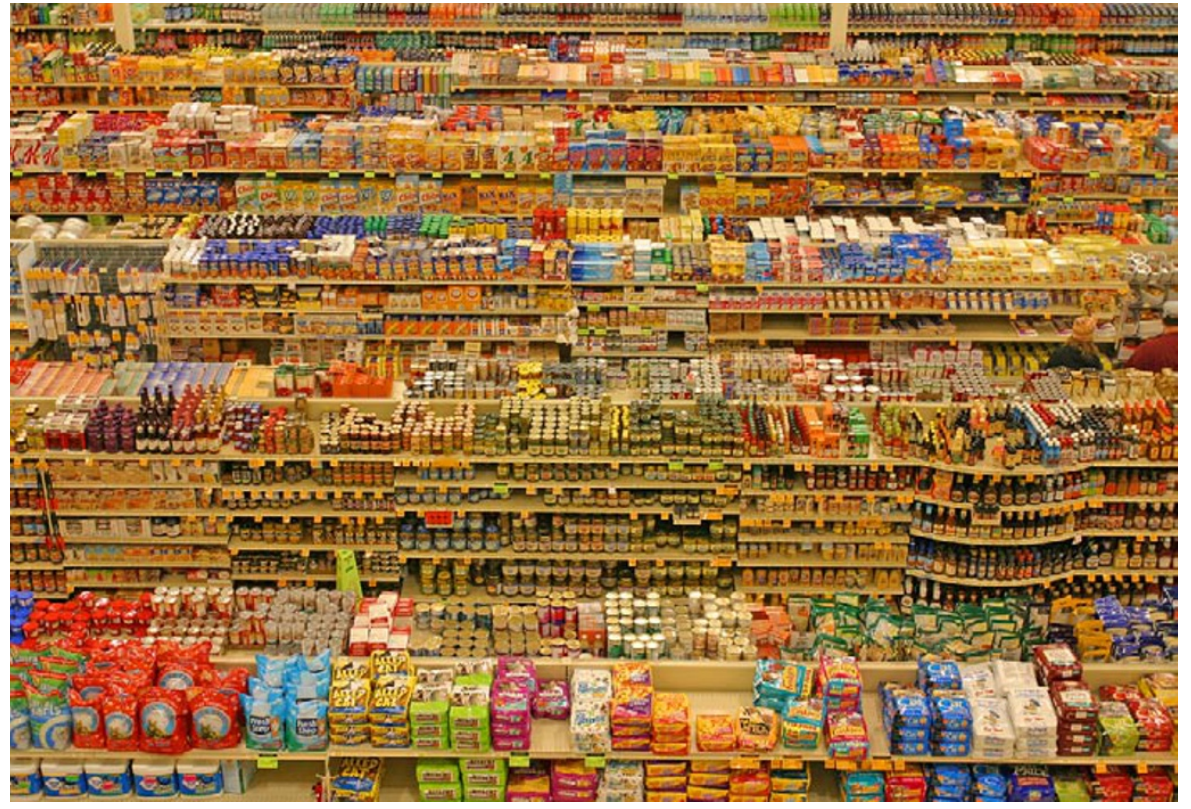

Sociology could further understanding of climate-related issues such as what drives society's consumption.

agglomerations - responsible between them for a third of US carbon emissions (in total there are over 3,000 such localities in the country).

\section{"The only solution lies in a level of global cooperation that humanity has never seen before."}

Jeffrey Broadbent

They looked at three features of each. The first was the level of risk the localities were facing from climate change, which the researchers measured using temperature changes over the past century, proximity to the coast, and a record of the area's prior history of adverse events - hurricanes, floods, droughts - that could be related to climate change. Second, they looked at each area's stress levels - not how anxious they were, but how much they affected the environment by producing carbon emissions through industry, for example. Finally, they took into account the political situation, looking at whether an area's constituents were predominantly Democrat or Republican.

What they found was discouraging but logical. "The most at risk and least responsible were most likely to participate, and the most responsible and least at risk were least likely," says Zahran. If it suited an area well to emit loads of carbon dioxide and it never suffered the consequences, then the area would be unlikely to participate actively in efforts to reduce emissions ${ }^{3}$.

Though the finding might sound obvious, thanks to Zahran's project it can now start to leave the realms of anecdote and assumption. This kind of study could be valuable to the federal government when making decisions on how to fight climate change in the face of such rationality. The fundamental question, says Zahran, is "How do you corral these states into participating in a program when the localities have such different starting points?"

His work has already identified 'hotspot clusters' - regions with similar risk and stress profiles - which policymakers can consider together when recommending plans of action. These hotspots also justify regional climate pacts like the cap-and-trade market already operating in ten states in the northeast corner of America, Zahran says.

Zahran's results also lead him to make some suggestions about how best to mitigate the effects of climate change. "Because the costs and benefits of both policy action and inaction are distributed unevenly by place, voluntary-participation programs at the local scale are likely to fail," he says. "The free-rider incentives are simply too high at the municipal level."

\section{CHANGING PRACTICES}

Zoom down another level to the typical American household, and you will find Thomas Dietz. One project of his looks at why levels of energy efficiency vary so widely between households in different nations - and how small changes in 
behaviour could help people use energy more efficiently. He and his colleagues have calculated that if a 'reasonable fraction' of people - estimated at 20 to 30 per cent - made small, environmentally beneficial changes, such as switching furnace filters or driving less aggressively, then overall household energy consumption could drop by up to 20 per cent. That's not even assuming that the majority of people would take such measures. "The rate of return is amazingly high," says Dietz.

So why hasn't everybody started doing these things? This is the core of what Dietz, Zahran and others are keen to understand. "Economic and social programs with [monetary] incentives can vary by a factor of ten in their uptake," Dietz says.

Sociologists are far from having a catch-all explanation for this variation. But the pattern that Zahran is seeing at the level of local government - that the selfish way out is the most often selected - might be playing out at the national level too. "There's been a relative failure of international agreements to change our greenhouse gas emissions," says Broadbent. "Both natural and political scientists have begun thinking about why nations aren't taking this more seriously."

There are plenty of other questions that sociology is well-placed to tackle. "There is such a long list," sighs Paul Stern. He highlights a few: How can we understand the consumption that drives climate change? Why do people desire larger houses for fewer people, and faster cars for more crowded roads? What's behind the public acceptance - or otherwise - of policies that seek to mitigate climate change, and of the scientific evidence they are based on? And why are there differences across countries?

\section{"There are a lot of valuable contributions that could be made, and very few of them have been made."}

Paul Stern

And then there's the next step. It's all very well coming up with a to-do list like this, but how can it all be put into practice? "What advice would I give government? I've been struggling with just that question," says Stern. "We definitely need to build scientific capacity in this area," he says - ensuring stable jobs and training for young researchers or building more interdisciplinary centres, for example. Another angle is to set challenges that are truly cross-disciplinary, says Hoskins. The Grantham Institute at Imperial College does just that, running projects that aim to design sustainable cities or decarbonize electricity. These are projects that call for a mixed bag of engineers, chemists, economists, town planners and sociologists. "Dealing with generalities, we just seem to float", he says, but "taking specifics seems to be quite useful." Sociology must overcome its own internal wrangling too. "We've been poking traditional sociologists in the ribs, saying, 'pay attention,"' says Brechin.
The take-home message is clear: it's all very well having a shiny new technique for burying carbon or turning plants into fuel, but "if we don't understand how society is going to perceive it, it might well backfire", Liverman says. The tools of natural science cannot help us ask what makes our culture so consumption-heavy, what determines how individuals or communities differ in their response to climate change, or what power dynamics are at play when governments negotiate their policies.

Consequently, "there's only so far we can go by understanding the science of the technologies needed to mitigate and adapt", says Hoskins. "In the end it's whether people will take them up."

In the words of Albion Woodbury Small, who in 1892 founded the first sociology department in the US at the University of Chicago, "Sociology was born of the modern ardor to improve society." And what better way to improve it now than to join the ranks of those tackling climate change?

Published online: 30 July 2009

doi:10.1038/climate.2009.73

References

1. Nagel, J., Dietz, T. \& Broadbent, J. Worskhop on Sociological Perspectives on Global Climate Change May 2008 (National Science Foundation, 2009); http://tiny.cc/sociology

2. Lever-Tracy, C. Curr. Sociol. 56, 445-466 (2008).

3. Zahran, S., Grover, H., Brody, S. D. \& Vedlitz, A Urban Affairs Review (in the press).

Kerri Smith is a podcast editor and reporter for Nature.

\title{
lce memory
}

\author{
Ice has become an unequalled resource for studying the Earth's climatic history. Anna Barnett \\ rounds up several new features on our site that pay tribute to the field of paleoclimatology, \\ from the initial discovery of climatic clues in ice through to current efforts to recover a core that \\ stretches back over a million years.
}

Some of scientists' gravest concerns about future climate change are rooted in the past. Records studied by paleoclimatologists reveal that the more extreme possibilities for this century and beyond - temperatures soaring, ice sheets vanishing, fertile lands withering into deserts - were realized previously on Earth when atmospheric greenhouse gas levels surged. This summer, experts working to understand how and why such changes occur met in Columbus, Ohio, at the Byrd Polar Research Centre, one of the world's top facilities for reconstructing past climates.

The scientists who gathered at the American Geophysical Union's Chapman Conference on Abrupt Climate Change, held 15-19 June, bring a diversity of tools to bear in understanding the past.
Among the proxies they use are ice cores, tree rings, corals and marine sediments. Though each has its own merits, ice cores have provided unparalleled insights into the nature of the Earth's climate system. Offering records of climatic history whose detail and completeness are unmatched, ice core data stretch back 800,000 years and are conveniently located in some of the world's most climatically sensitive regions. 